\title{
Effectiveness of Self-regulation of Emotion Modules to Reduce Negative Aggressive Behavior of Students
}

\author{
Purwadi, Wahyu Nanda Eka Saputra", Said Alhadi, Amien Wahyudi, Agus Supriyanto, Siti Muyana
}

Department of Guidance and Counseling, Universitas Ahmad Dahlan, Indonesia

Received February 6, 2020; Revised April 2, 2020; Accepted April 19, 2020

Copyright $\bigcirc 2020$ by authors, all rights reserved. Authors agree that this article remains permanently open access under the terms of the Creative Commons Attribution License 4.0 International License

\begin{abstract}
The problem of aggressive behavior is continuously more developing in form and intensity. The impact felt by victims and perpetrators of aggressive behavior is also more and more complex. One way to reduce aggressive behavior is to train students in self-regulation of emotion, for which in this study, the exercises are done with the help of modules. The purpose of this study is to determine the effectiveness of the self-regulation of emotion modules to reduce aggressive behavior. This study uses a quasi-experimental type with a nonequivalent control group design. The instrument used in this study was a scale of aggressive behavior. The data analysis technique used is the independent sample t-test. The results of the study concluded that there was a significant difference in the aggressive behavior of students, who reduced trough self-regulation of emotion module interventions from students who reduced traditional counseling interventions. The aggressive behavior of students, who reduced the self-regulation of emotion module intervention was lower than the aggressive behavior of students who reduced traditional counseling interventions.
\end{abstract}

Keywords Aggressive Behavior, Self-regulation of Emotion, Modules

\section{Introduction}

"Bhineka Tunggal Ika" is the primary motto of the Indonesian people, which is upheld by every citizen of Indonesia, including implemented in the school environment [1], [2]. The motto has the meaning that the Indonesian people have a variety of cultures, but they remain a unity. These cultural differences can lead to problems if there aren't supports by the strong characteristics each Indonesian has. Therefore, character education to be implemented well in the educational settings of the era of the industrial revolution [3]. One of the characteristics that need to be built by adolescents is self-regulation [4]-[6]. This ability of self-regulation includes self-regulation of emotion, which adolescents need to have the ability to be able to regulate the emotions that exist in themselves precisely and with their skills.

In the era of the industrial revolution 4.0, various shocks and problems arise in adolescents, both intrapersonal and interpersonal issues in schools. These problems can trigger other items when they are not competent to regulate emotions, and other issues arise that can harm themselves and others. Thus, it becomes a need for adolescents to be capable of foster comprehensible emotions when they are dealing with specific problems. The ability of adolescents to express bright emotions is related to adolescent depression and other psychopathological issues [7], [8].

The inability of adolescents to regulate the emotions that exist in themselves has an impact on the emergence of other forms of maladaptive behavior, one of which is aggressive behavior [9], [10]. This aggressive behavior is one of the instincts that exist in every human, which in Freud's concept of psychoanalysis is called Thanatos [11]. Also, adolescents who show aggressive behavior, this is because they are not able to suppress the feelings of frustration they experience, so they overflow in these destructive behaviors [12].

The problem of aggressive behavior is in the spotlight in Indonesian schools, even has caused death victims. The level of aggressive behavior of Vocational high-school students in Yogyakarta City, Indonesia is extremely tall at $5 \%$; lofty category by $26 \%$; average category by $40 \%$; nasty category by $21 \%$; very base categories by $8 \%$ [13]. The aggressive behavior of students in Yogyakarta, Indonesia at the junior high school level was in the excessively towering category at $1 \%$; high category $13 \%$; medium category $37 \%$; paltry category $43 \%$; a very low category of $6 \%$ [14]. In fact, the level of aggressive behavior of male and female students in Yogyakarta, Indonesia at the vocational high school level tends to be the 
same [15]. Problems caused aggressive behavior in the spotlight in schools.

One of the factors causing the emergence of aggressive behavior in adolescents is the failure of students to regulate the emotions that exist in themselves. The inability of adolescents to regulate emotions can affect various problems and psychopathological risks to adolescents [16]-[19]. Based on these data, it becomes the basis for school counselors to build good self-regulation of emotion skills so that they can suppress aggressive behavior that is often raised.

In this study, the counselor trains the ability of self-regulation of emotion with the help of modules. This compiled module can facilitate students to learn and practice independently in the self-regulation of emotion. Self-regulation of emotion consists of seven components, namely receiving, evaluating, triggering, searching, formulating, implementing, and assessing [20]. Thus, the purpose of this study is to determine the effectiveness of self-regulation emotion modules for reducing aggressive behavior. The results of this study are the reference for school counselors in their efforts to help students overcome their aggressive behavior.

Previous studies have found that modules of self-regulation of emotion are right appropriate for school counselors to implement in helping students reduce aggressive behavior [21]. Another research also concludes that self-regulation is a way for counselors to help students reduce aggressive behavior by students [22]. These studies provide a basis for strengthening the testing of the regulation of emotion modules to reduce aggressive behavior.

\section{Method}

\subsection{Research Design}

This experimental study uses a quasi-experimental type with a nonequivalent control group, experiment research design. The subjects involved in this study were 84 students who were divisible into two groups by not randomly. The model is not the same as the true experimental type, where two groups are divided into two randomly. One group became an experimental group that applied intervention self-regulation of emotion modules, and one group implemented conventional counseling intervention.

\subsection{Data Collection}

This study uses an aggressive behavior scale (ABS) instrument. ABS is divided using four aspects of aggressive behavior, namely, physical aggression, verbal aggression, anger, and hostility [23]. ABS consists of 29 items that are declared valid with coefficients of 0,321 to 0 ,
769. The reliability coefficient on this instrument is 0,871 (the high category).

\subsection{Subject of Study}

Subjects involved in this study were 84 junior-high-school students in a specialized area of Yogyakarta who had a high level of aggressive behavior. The research subjects were divided into two groups. Unlike true experimental design studies, in these quasi-experimental design study groups aren't divided randomly. One group was called an experimental group that reduced intervention self-regulation of emotion modules, and one group was called a control group that reduced a conventional counseling intervention. The subjects of this study were determined using a simple random sampling technique after the chosen subjects implemented an instrument in the form of a questionnaire to be able to know the condition of students' self-regulation emotion.

\subsection{Research Stages}

This research was conducted in seven stages. First, the research team formulated research objectives. Second, the research team formulated the research design and division of work of the research team. Third, formulate data collection instruments. Fourth, test the instrument to determine the validity and reliability of the instrument. Fifth, spread the instruments to do the pretest. Sixth, conduct counseling interventions, both in the experimental and control groups. Seventh, conduct posttest and analysis of research data to determine the effectiveness of self-regulation of emotion to reduce aggressive behavior.

\subsection{Data Analysis Technique}

Data analysis techniques for this study used independent sample $t$ tests. This data analysis technique is a parametric test to identify significant differences in mean or mean between two free groups with interval / ratio data scales. The two free groups referred here are two groups that are not paired; meaning the source of data comes from different subjects. The results of this data analysis are a comparison of the level of aggressive behavior of groups of students who reduced the intervention self-regulation of emotion modules and groups of students who implemented conventional counseling interventions.

\section{Results}

The feasibility of the product or modules has been rating by the experts and the practitioner's judgment. The following table shows the product feasibility by the expert and practitioner. Cohen's Kappa Coefficient Inter-rater reliability analysis showed that there is a significant 
agreement between expert and the practitioner in the level of $5 \%$ significance related to the product being developed [21].

Table 1. Results of Expert's and Practitioner's Judgment

\begin{tabular}{|l|l|}
\hline Aspect & Average Score \\
\hline Product overview & 3,07 \\
\hline $\begin{array}{l}\text { Product accuracy in reducing aggressive } \\
\text { behavior }\end{array}$ & 3,27 \\
\hline $\begin{array}{l}\text { Product usability for counselor in reducing } \\
\text { students' aggressive behavior }\end{array}$ & 3,1 \\
\hline Average & 3,18 \\
\hline
\end{tabular}

Data analysis techniques using the Independent sample t-test require several assumptions that must do. The first assumption is that both data distributed. The normality test in this study uses the Kolmogorov-Smirnov analysis described in table 2 .

Table 2. Test of Kolmogorov-Smirnov

\begin{tabular}{|c|c|c|c|c|}
\hline \multirow{2}{*}{} & \multirow{2}{*}{ Strategy } & \multicolumn{3}{|c|}{ Kolmogorov-Smirnov } \\
\cline { 3 - 5 } & & Statistic & df & Sig. \\
\hline \multirow{2}{*}{ AggrBehav } & 1,00 &, 129 & 42 &, 078 \\
\cline { 2 - 5 } & 2,00 &, 128 & 42 &, 079 \\
\hline
\end{tabular}

In table 2, described that the coefficient Sig. in the group of students who implemented the intervention self-regulation of emotion modules was 0,078 and the coefficient Sig. in the group of students who applied conventional counseling interventions was 0,079 . Sig coefficient. In both groups is higher than 0,05 . Based on these coefficients, it is the conclusion that the two data distributed, so the first assumption, that is, normally distributed data, has been fulfilled.

The second assumption in this study is comparable data - the homogeneity test described in table 3.

Table 3. Test of Homogeneity of Variance

\begin{tabular}{|c|c|c|c|c|c|}
\hline \multicolumn{2}{|c|}{} & $\begin{array}{c}\text { Levene } \\
\text { Statistic }\end{array}$ & df1 & df2 & Sig. \\
\hline \multirow{4}{*}{$\begin{array}{c}\text { Aggr } \\
\text { Behav }\end{array}$} & Based on Mean &, 000 & 1 & 82 &, 994 \\
\cline { 2 - 6 } & $\begin{array}{c}\text { Based on Median and with } \\
\text { adjusted df }\end{array}$ &, 000 & 1 & 82 & 1,000 \\
\cline { 2 - 6 } & Based on trimmed mean &, 000 & 1 & 81,995 & 1,000 \\
\hline
\end{tabular}

The table above shows the homogeneity test results with Levene's test method. The Levene's value pictured in the Value-based on the Mean row is 0,000 with the Sig coefficient. Amounted to 0,994 , it was higher than 0,05 , which means there is a similarity between the variances between groups or, which means homogeneous. Thus, the second assumption in this study has been according to the hypothesis.

After the assumption test is carried out and analyzed using the Independent sample t-test. The results of the analysis using the Independent sample t-test found that there were significant differences in the level of aggressive behavior in the group of students who reduced self-regulation of emotion module's interventions with groups of students who implemented conventional counseling interventions. Based on the average level of aggressive behavior, students who implementation self-regulation of emotion modules had lower levels of aggressive behavior compared to the group of students who implemented conventional counseling interventions. The results of data analysis using SPSS and assisted Independent sample t-test can be described in Tables 4 and 5 .

Table 4. Group statistics

\begin{tabular}{|c|c|c|c|c|c|}
\hline & Strategy & $\mathrm{N}$ & Mean & Std. Deviation & Std. Error Mean \\
\hline \multirow{2}{*}{$\begin{array}{c}\text { Aggr } \\
\text { Behav }\end{array}$} & 1,00 & 42 & 78,7619 & 10,93620 & 1,68749 \\
\cline { 2 - 6 } & 2,00 & 42 & 95,7619 & 10,97849 & 1,69402 \\
\hline
\end{tabular}

In table 4 , the statistical group can describe that $\mathrm{N}$ is 42 for each treatment. The mean of the experimental group is 78.7619 , and the control group is 95.7619. The values of standard deviation and standard error of the experimental group were lower than the control group. The standard error from mean is to describe the average distribution of a sample against the ordinary all possible samples.

In table 4, it appears that the fobtained is 0,000 with a significance of 0,994 , which means it is higher than 0,05 $(0,994>0,05)$. The variant of the population group is homogeneous. The homogeneity requirements for comparative analysis are met. The results of the data analysis obtained a coefficient of $t$ count of $-7,110$ with a probability of 0,000 . The probability of 0,000 when compared to 0,05 , is smaller, which means there are differences in aggressive student behavior between groups given the intervention self-regulation of emotion modules and groups that implemented conventional counseling interventions. If analyzed based on the average score of aggressive behavior, the count of aggressive behavior groups of students who reduced self-regulation of emotion modules intervention was lower $(78,7619)$ than the scores of aggressive behavior of groups of students who implementation conventional counseling interventions $(95,7619)$. It can conclude that the aggressive behavior of students who reduced self-regulation of emotion modules interventions decreases more significantly than students who implemented conventional counseling interventions. 
Table 5. Independent sample test

\begin{tabular}{|c|c|c|c|c|c|c|c|}
\hline \multicolumn{2}{|c|}{} & \multicolumn{2}{|c|}{$\begin{array}{c}\text { Levene's Test for Equality of } \\
\text { Variances }\end{array}$} & \multicolumn{4}{c|}{ t-test for Equality of Means } \\
\cline { 3 - 8 } & $\mathrm{F}$ & Sig. & $\mathrm{t}$ & $\mathrm{df}$ & Sig. (2-tailed) & Std. Error Difference \\
\hline \multirow{3}{*}{ Aggr Behav } & $\begin{array}{c}\text { Equal variances } \\
\text { assumed }\end{array}$ &, 000 &, 994 & $-7,110$ & 82 & 2,39109 & $-17,00000$ \\
\cline { 2 - 8 } & $\begin{array}{c}\text { Equal variances } \\
\text { not assumed }\end{array}$ & & & $-7,110$ & 81,99 & 2,39109 & $-17,00000$ \\
\hline
\end{tabular}

\section{Discussion}

The results of the study concluded that self-regulation modules could effectively help students reduce aggressive behavior. The conclusion described that the aggressive behavior within the group of students who implemented the self-regulation of the emotion module's intervention was lower than the score of the group's aggressive behavior of students who implemented conventional counseling interventions. The results from this study prove that school counselors can utilize self-regulation of emotion modules to help students reduce aggressive behavior.

Aggressive behavior is still a severe problem that occurs in adolescents where this behavior involves elements such as biological elements, personality development, social processes, basic cognitive processes, short-term and long-term processes, and decision-making processes [24]. Aggressive behavior is a form of action that intentionally hurts others, both physically and non-physically. Aggressive behavior is a complex phenomenon that operates at several levels, with different meanings, and application through diverse forms of violent behavior [25]. Aggressive behavior is physical or verbal behavior that aims to hurt others [26]. Aggressive behavior is born to respond to threats (according to perception or existence) originating from other individuals or groups outside the group [27].

Aggressive behavior as behavior or behavioral tendencies whose intention is to hurt others both physically and psychologically with the aggressiveness itself has four aspects, namely verbal aggression, anger, hostility, physical aggression [23]. These four aspects of aggressive behavior form the basis of the preparation of instruments in this study, precisely the scale of aggressive behavior. Even now, there is also a new aggressive face, online aggression [28]-[31]. This aggressive behavior model shown by adolescence by sending messages is aimed at hurting others through social media. This aggressive behavior model can be used in a manner today internationally, especially in Indonesia.

One way to reduce aggressive behavior is to help students learn to optimize the self-regulation of emotion. Self-regulation of emotions is used for someone in regulating expression, making decisions, and others. Emotional regulation is an intrinsic experience that produces emotions and is, after that, informed of cognitive abilities to give emotion an influence and sense of behavior
[32]. Emotions occur from a stimulus in a person and next reflected into action.

Emotional regulation becomes one of the aspects of concern for individuals who engage in aggressive behavior. Various studies have concluded that the high or low level of aggressive behavior of students is affected by the high or low ability of students to regulate their emotions [10], [33]. The strength is the basis for counselors to develop the skill of self-regulation of emotion to help students get out of aggressive behavior problems that are often occurring. Another literature also mentions that self-regulation of emotion is an alternative strategy for counselors to reduce aggressive behavior [34].

Humans can regulate the emotions that exist in themselves, of course, in their way too. One of the literature states that someone regulates the emotions that exist in him caused by two motives, namely hedonistic and instrumental motives [35]. People, who pursue hedonistic purposes, look for emotions to increase the ratio of pleasure that exists in themselves to the pain that is occurring. Whereas people who have instrumental goals, they target the potential benefits of emotions apart from their direct phenomenology. A school counselor, who facilitates the development of self-regulation of emotion, encourages students to have instrumental motives, so they can look for potential benefits when regulating their emotions, and can reduce aggressive behavior.

Self-regulation of emotion can improve symptoms of anxiety, depression, and self-esteem of individual users of the substance. Activities in the self-regulation of emotion training stage focus on breathing (not focus on distractions), thus showing changes, namely (a) reducing the experience of negative emotions, (b) reducing amygdala activity, and (c) increasing activity in the brain involved in attention dissemination [36]. Self-regulation of emotion generally consists of receiving or accepting, evaluating or evaluating, triggering or making a change, searching or finding a solution, formulating or designing a plan, implementing or implementing a strategy, assessing or measuring the effectiveness of the approach that has been a plan.

In this study, counselors facilitate students to learn to optimize the self-regulation of emotion by using modules. The results of research on the use of modules stated that the learning process of students who use the help of modules could encourage students to solve problems collaboratively, clarify their roles, and provide information from their perspectives [37]. Based on these results, it can reveal facts 
that a student who learns self-regulation of emotion by using modules, can learn independently to solve aggressive behavior problems according to their perspectives and ways.

Modules used to help students develop self-regulation of emotion to reduce aggressive behavior categorized as appropriate for use by counselors [21]. The principal components in the module consist of six elements, namely receiving, evaluating, triggering, searching, formulating, implementing, and assessing [21]. The seven principal components in the self-regulation of emotion modules can facilitate students to reduce aggressive behavior that is occurring. In this research process, students are training in emotional self-regulation skills that have been explained in detail in the module, thus leading to a directive method in which students must be more active in applying emotional self-regulation skills.

This research is supported by other studies, which conclude that Emotion-Related Self-Regulation can assist students in improving student adjustment in the school environment [38]. However, in this study, self-regulation of emotion was used to enhance student adjustment, while this study can reduce aggressive behavior. In this study also self-regulation of emotion did not involve students' independence in learning. In this study, the emphasis was on the aspect of student independence in education because the self-regulation of emotion can be developed with help of modules.

Other studies have concluded that self-regulation of emotion strategies can be used by counselors to reduce aggressive behavior effectively [39]. However, in this study, the identified aggressive behavior focused on aspects of physically and relationally aggressive behavior. In contrast, in this study, aggressive behavior was recognized with more specific forms, namely physical, verbal, anger, and hostility. The study was also implemented on preschool children. So emotional regulation strategies still can be discussed whether children of this age applied with emotional regulation strategies. In contrast to study in which the subjects involved were junior high school-aged children, which was in terms of developmental level, they could train themselves to regulate the emotions that exist in themselves.

Other studies also concluded that emotion regulation influences aggressive behavior that arises because of the provocation from others [40]. However, this research can't be classified as correlation research, and there is no attempt to identify the effect of specific strategies implemented by counselors to reduce aggressive behavior. Whereas, this study ranked as experimental research, which aims to test the effectiveness of self-regulation of emotion modules to reduce aggressive behavior. In this study also the identified aggressive behavior was limited to aggressive behavior in the face of provocation or reactive aggressive behavior, whereas in this study, the aggressive behavior could be in the form of reactive or proactive behavior.
Aggressive behavior that can be minimized, can suppress the emergence of negative perceptions of the school climate in students. Negative perceptions of the school climate are proven to reduce academic performance [41]. School counselors can make various efforts to suppress the emergence of aggressive behavior, among others by using the help of the self-regulation of emotion module [21], implementing a peace counseling approach [42], and solution-focused briefing counseling [43].

This study has limitations. One limitation of this study is the research design that uses a quasi-experimental design, and the two groups aren't randomly divided like true experimental design research. In subsequent studies, the assignment of research subjects to the experimental and control groups should be implemented randomly (Random Assignment), so that the internal validity is high.

\section{Conclusions}

Aggression behavior becomes a problem that has increasingly high complexity. In this research, it has revealed that one of the counseling techniques that used self-regulation of emotion modules can be used to help students reduce aggressive behavior. Counselors help counselees develop self-regulation of emotion by involving seven principal components, namely receiving, evaluating, triggering, searching, formulating, implementing, and assessing. This research should be a reference for counselors to use self-regulation of emotion modules to help the guidance and counseling program in building a culture of peace in the school environment.

\section{Acknowledgments}

Thank you to the Ministry of Research and Technology of the Republic of Indonesia for providing material support for this research. A thank you also to Universitas Ahmad Dahlan for facilitating the completion of this research and producing new work, namely the self-regulation of emotion modules.

\section{REFERENCES}

[1] M. I. Farisi, "Bhinneka Tunggal Ika [Unity in Diversity]: From Dynastic Policy to Classroom Practice," J. Soc. Sci. Educ., vol. 13, no. 3, pp. 83-89, 2014, doi: 10.2390/jsse.

[2] I. Hambali and M. Gipayana, "A cognitive stage-experiential psycho-educational guidance model to enhance the Bhineka Tunggal Ika (Unity in diversity) awareness," J. Soc. Sci., vol. 5, no. 1, pp. 19-28, 2016, doi:10.25255/jss.2016.5.1.1 9.28 .

[3] O. R. P. R. Linge, F. Khoirunnisa, and F. S. Silitonga, 
"Character Education Based on Psychology Perspective in the Industrial Revolution Era 4.0," vol. 295, no. ICETeP 2018, pp. 263-265, 2019, doi: 10.2991/icetep-18.2019.63.

[4] P. Alex Linley et al., "Character strengths in the United Kingdom: The VIA Inventory of Strengths," Pers. Individ. Dif., vol. 43, no. 2, pp. 341-351, 2007, doi: 10.1016/j.paid.2006.12.004.

[5] C. Seligman, Martin E.P., Park, Nansook and Peterson, "The VIA classification of character strengths," VIA Institute on Character. 2004

[6] Via Institute On Character, "Character Strengths, Character Building Experts: VIA Character," Via Institute On Character, 2017. [Online]. Available: https://www.viachar acter.org/www/.

[7] J. Gruber et al., "Positive Emotion Specificity and Mood Symptoms in an Adolescent Outpatient Sample," Cognit. Ther. Res., vol. 41, no. 3, pp. 393-405, 2017, doi: 10.1007/s10608-016-9796-7.

[8] A. D. Kendall et al., "Measuring Positive Emotion with the Mood and Anxiety Symptom Questionnaire," Assessment, vol. 23, no. 1, pp. 86-95, 2016, doi: 10.1177/10731911155 69528

[9] D. S. Chester, L. M. Merwin, and C. N. Dewall, "Maladaptive perfectionism's link to aggression and self-harm: Emotion regulation as a mechanism," Aggress. Behav., vol. 41, no. 5, pp. 443-454, 2015, doi: 10.1002/ab. 21578

[10] T. Roberton, M. Daffern, and R. S. Bucks, "Emotion regulation and aggression," Aggress. Violent Behav., vol. 17, no. 1, pp. 72-82, 2012, doi: 10.1016/j.avb.2011.09.006.

[11] F. Caropreso, "The death instinct and the mental dimension beyond the pleasure principle in the works of Spielrein and Freud," Int. J. Psychoanal., vol. 98, no. 6, pp. 1741-1762, 2017, doi: 10.1111/1745-8315.12630.

[12] G. Eissa and S. W. Lester, "Supervisor role overload and frustration as antecedents of abusive supervision: The moderating role of supervisor personality," J. Organ. Behav., vol. 38, no. 3, pp. 307-326, 2017, doi: 10.1002/job.2123.

[13] W. N. Saputra and I. B. Handaka, "Perilaku Agresi Pada Siswa SMK di Yogyakarta," Jurnal Fokus Konseling, vol. 4, no. 1, pp. 1-8, 2018.

[14] S. Alhadi, P. Purwadi, S. Muyana, W. N. E. Saputra, and A. Supriyanto, "Agresivitas Siswa SMP di Yogyakarta," J. Fokus Konseling, vol. 4, no. 1, p. 93, 2018, doi: 10.26638/jfk.507.2099.

[15] W. N. E. Saputra, N. Hanifah, and D. N. Widagdo, "Perbedaan Tingkat Perilaku Agresi Berdasarkan Jenis Kelamin pada Siswa Sekolah Menengah Kejuruan Kota Yogyakarta," J. Kaji. Bimbing. dan Konseling, vol. 2, no. 4, pp. 142-147, 2017, doi: 10.17977/um001v2i42017p142.

[16] K. A. McLaughlin, M. L. Hatzenbuehler, D. S. Mennin, and S. Nolen-Hoeksema, "Emotion dysregulation and adolescent psychopathology: A prospective study," Behav. Res. Ther., vol. 49, no. 9, pp. 544-554, 2011, doi: $10.1016 /$ j.brat.2011.06.003.

[17] K. Keenan, "Emotion Dysregulation as a Risk Factor for
Child Psychopathology," Clin. Psychol. Sci. Pract., vol. 7, no. 4, pp. 418-434, 2000, doi: 10.1093/clipsy/7.4.418.

[18] T. P. Beauchaine and D. Cicchetti, "Emotion dysregulation and emerging psychopathology: A transdiagnostic, transdisciplinary perspective," Development and Psychopathology, vol. 31, no. 3. pp. 799-804, 2019, doi: $10.1017 / \mathrm{S} 0954579419000671$

[19] A. Bazarnik, "Emotion dysregulation and psychopathology in epilepsy," Pol. Merkur. Lekarski, vol. 44, no. 264, pp. 302-307, 2018.

[20] B. J. Knox, R. G. Lugo, Ø. Jøsok, K. Helkala, and S. Sütterlin, "Towards a Cognitive Agility Index: The Role of Metacognition in Human Computer Interaction," in International Conference on Human-Computer Interaction, 2017, vol. 1, pp. 243-250.

[21] S. Alhadi, W. N. E. Saputra, Purwadi, A. Wahyudi, A. Supriyanto, and S. Muyana, "Self-regulation of Emotion Module to Reduce Aggressive Behavior," Advances in Social Science, Education and Humanities Research, vol. 387, pp. 23-26, 2020, doi: 10.2991/icei-19.2019.6.

[22] C. N. DeWall, R. F. Baumeister, T. F. Stillman, and M. T. Gailliot, "Violence restrained: Effects of self-regulation and its depletion on aggression," J. Exp. Soc. Psychol., vol. 43, no. 1, pp. 62-76, 2007, doi: 10.1016/j.jesp.2005.12.005.

[23] A. H. Buss and M. Perry, "The Aggression Questionnaire," J. Pers. Soc. Psychol., vol. 63, no. 3, pp. 452-459, 1992, doi: 10.1037/0022-3514.63.3.452.

[24] C. N. Dewall, C. A. Anderson, and B. J. Bushman, "The general aggression model: Theoretical extensions to violence," Psychol. Violence, vol. 1, no. 3, pp. 245-258, 2011, doi: 10.1037/a0023842.

[25] J. M. Ramirez, "Some dychotomous classifications of aggression according to its function," J. Organ. Transform. Soc. Chang., vol. 6, no. 2, pp. 85-101, 2009, doi: 10.1386/jots.6.2.85_1.

[26] D. Myers, Social psychology. New York: Mc Graw-Hill, 2012.

[27] V. V. MacLaren, L. A. Best, and E. E. Bigney, "Aggression-hostility predicts direction of defensive responses to human threat scenarios," Pers. Individ. Dif., vol. 49, no. 2, pp. 142-147, 2010, doi: 10.1016/j.paid.2010.03.024.

[28] D. M. Law, J. D. Shapka, J. F. Domene, and M. H. Gagné, "Are Cyberbullies really bullies? An investigation of reactive and proactive online aggression," Comput. Human Behav., vol. 28, no. 2, pp. 664-672, 2012, doi: 10.1016/j.chb.2011.11.013.

[29] D. M. Law, J. D. Shapka, and B. F. Olson, "To control or not to control? Parenting behaviours and adolescent online aggression," Comput. Human Behav., vol. 26, no. 6, pp. 1651-1656, 2010, doi: 10.1016/j.chb.2010.06.013.

[30] A. G. Zimmerman and G. J. Ybarra, "Online aggression: The influences of anonymity and social modeling.," Psychol. Pop. Media Cult., vol. 5, no. 2, pp. 181-193, 2016, doi: $10.1037 / \mathrm{ppm} 0000038$

[31] N. E. Werner, M. F. Bumpus, and D. Rock, "Involvement in internet aggression during early adolescence," J. Youth 
Adolesc., vol. 39, no. 6, pp. 607-619, 2010, doi: 10.1007/s10964-009-9419-7.

[32] M. Vandekerckhove, C. Von Scheve, S. Ismer, S. Jung, and S. Kronast, Regulating Emotions: Culture, Social Necessity, and Biological Inheritance. Australia: Blackwell Publishing, 2009.

[33] T. N. Sullivan, R. C. Garthe, E. A. Goncy, M. M. Carlson, and K. L. Behrhorst, "Longitudinal Relations between Beliefs Supporting Aggression, Anger Regulation, and Dating Aggression among Early Adolescents," J. Youth Adolesc., vol. 46, no. 5, pp. 982-994, 2017, doi: 10.1007/s10964-016-0569-0.

[34] P. Purwadi and S. Said Alhadi, "Self-Regulation of Emotion as an Alternative to Reduce Student's Aggressiveness," $A d v$. Soc. Sci. Educ. Humanit. Res., vol. 173, pp. 2003-2005, 2018, doi: 10.2991/icei-17.2018.69.

[35] M. Tamir, "Why Do People Regulate Their Emotions? A Taxonomy of Motives in Emotion Regulation," Personal. Soc. Psychol. Rev., vol. 20, no. 3, pp. 199-222, 2016, doi: $10.1177 / 1088868315586325$.

[36] P. R. Goldin and J. J. Gross, "Effects of Mindfulness-Based Stress Reduction (MBSR) on Emotion Regulation in Social Anxiety Disorder," Emotion, vol. 10, no. 1, pp. 83-91, 2010, doi: $10.1037 / \mathrm{a} 0018441$.

[37] P. Solomon et al., "Students' perceptions of interprofessional learning through facilitated online learning modules," Med. Teach., vol. 32, no. 9, pp. 391-398, 2010, doi: 10.3109/0142159X.2010.495760.

[38] N. Eisenberg, T. L. Spinrad, and N. D. Eggum, "Emotion-Related Self-Regulation and Its Relation to Children's Maladjustment," Annu. Rev. Clin. Psychol., vol. 6 , no. $1, \mathrm{pp}$.

495-525, 2010, doi: 10.1146/annurev.clinpsy.121208.1312 08 .

[39] J. Helmsen and F. Petermann, "Emotion regulation strategies and aggressive behavior of preschool children," Prax. Kinderpsychol. Kinderpsychiatr., vol. 59, no. 10, pp. 775791, 2010, doi: 10.13109/prkk.2010.59.10.775.

[40] J. L. Vaydich, "The influence of emotion regulation on aggressive behavior in the face of provocation," 2011.

[41] W. N. E. Saputra, A. Supriyanto, B. Astuti, Y. Ayriza, and S. Adiputra, "The Effect of Student Perception of Negative School Climate on Poor Academic Performance of Students in Indonesia," Int. J. Learn. Teach. Educ. Res., vol. 19, no. 2, pp. 279-291, 2020

[42] W. N. E. Saputra et al., "Peace Counseling Approach (PCA) to Reduce Negative Aggressive Behavior of Students," Univers. J. Educ. Res., vol. 8, no. 2, pp. 631-637, 2020.

[43] C. D. Wiretna, W. N. E. Saputra, A. Muarifah, and M. Barida, "Effectiveness of solution-focused brief counseling to reduce online aggression of student," Univers. J. Educ. Res., vol. 8, no. 3, pp. 1092-1099, 2020. 